\title{
Correction of target-controlled infusion following wrong selection of emulsion concentrations of propofol
}

\author{
Yun-Jeong Chae, Han Bum Joe, Won-Il Lee, Jin-A Kim, and Sang-Kee Min \\ Department of Anesthesiology and Pain Medicine, Ajou University School of Medicine, Suwon, Korea
}

Background: We investigated the correction methods following wrong-settings of emulsion concentrations of propofol as a countermeasure against erroneous target-controlled infusions (TCI).

Methods: TCIs were started with targeting $4.0 \mu \mathrm{g} / \mathrm{ml}$ of effect-site concentration $\left(\mathrm{C}_{\text {eff }}\right)$ of propofol, and the emulsion concentrations were selected for $2.0 \%$ instead of $1.0 \%\left(\mathrm{FALSE}_{1-2}, \mathrm{n}=24\right)$, or $1.0 \%$ instead of $2.0 \%\left(\mathrm{FALSE}_{2-1}, \mathrm{n}=24\right)$. These wrong TCIs were corrected at $3 \mathrm{~min}$ after infusion start. During FALSE1-2, the deficit was filled up while injecting after equilibrium $(n=12)$, or while overriding $(n=12)$. During FALSE $E_{2-1}$, the overdose was evacuated while targeting $C_{\text {eff }}(n=$ 12) or targeting plasma concentration $\left(C_{p}\right)(n=12)$. The gravimetrical measurements of TCI reproduced the $C_{p}$ and $C_{\text {eff }}$ using simulations. The reproduced $\mathrm{C}_{\text {eff }}$ at $3 \mathrm{~min}\left(\mathrm{C}_{\text {eff-3min }}\right)$ and the time to be normalized within $\pm 5 \%$ of $\operatorname{target} \mathrm{C}_{\text {eff }}\left(\mathrm{T}_{ \pm 5 \%}\right)$, were compared between the correction methods.

Results: During the wrong TCI, $\mathrm{C}_{\text {eff-3min }}$ was $1.98 \pm 0.01 \mu \mathrm{g} / \mathrm{ml}$ in FALSE ${ }_{1-2}$, and $7.99 \pm 0.05 \mu \mathrm{g} / \mathrm{ml}$ in FALSE $2-1$. In FALSE $E_{1-2}, \mathrm{~T}_{ \pm 5 \%}$ was significantly shorter when corrected while overriding $(3.9 \pm 0.25 \mathrm{~min})$, than corrected after equilibrium $(6.9 \pm 0.05 \mathrm{~min})(\mathrm{P}<0.001)$. In $\mathrm{FALSE}_{2-1}, \mathrm{~T}_{ \pm 5 \%}$ was significantly shorter during targeting $\mathrm{C}_{\mathrm{p}}(3.6 \pm 0.04 \mathrm{~min})$ than targeting $\mathrm{C}_{\text {eff }}(6.7 \pm 0.15 \mathrm{~min})(\mathrm{P}<0.001)$.

Conclusions: The correction methods, based on the pharmacokinetic and pharmacodynamic characteristics, could effectively and rapidly normalize the wrong TCI following erroneously selections of the emulsion concentration of propofol. (Korean J Anesthesiol 2014; 66: 377-382)

Key Words: Drug delivery systems, Infusion pumps, Intravenous infusion, Propofol.

Received: January 13, 2014. Revised: February 24, 2014. Accepted: February 25, 2014.

Corresponding author: Sang-Kee Min, M.D., Department of Anesthesiology and Pain Medicine, Ajou University School of Medicine, San 5, Woncheon-dong, Paldal-gu, Suwon 442-721, Korea. Tel: 82-31-219-5572, Fax: 82-31-219-5579, E-mail: anesmin@nate.com

(c) This is an open-access article distributed under the terms of the Creative Commons Attribution Non-Commercial License (http:// creativecommons.org/licenses/by-nc/3.0/), which permits unrestricted non-commercial use, distribution, and reproduction in any medium, provided the original work is properly cited. 


\section{Introduction}

There are various kinds of errors possible while starting the target-controlled infusion (TCI) of anesthetics, resulting from mechanical causes or the wrong selection of TCI settings. A mechanical error of the infusion assembly of a TCI device was reported as a start-up delay that prolonged the stable state of infusion $[1,2]$. However, this kind of inaccuracy could be normalized as time passed, while the infusion system established stability. On the other hand, when settings of TCI variables are mistaken, such as patient-covariates, syringe brand compatibility [3], and drug name or diluent concentration, an estimation of the consequences will still be difficult.

The Diprifusor ${ }^{(}$for propofol with an automatic security tag system using a radio-frequency technology [4] can prevent the possibility to select the wrong emulsion concentration. However, all TCI machines are not equipped with automatic drug-recognizing systems. Accordingly, sometimes, if various emulsions of propofol were concomitantly prepared in the same anesthetic units, or if the TCI were prepared using various drug-infusion protocols saved in the TCI workstation, this kind of error-setting could be encountered. In our institute, such an error setting was found after the initiation of TCI and the wrong TCI was to be given up and switched to a zero-order continuous infusion pattern.

Therefore, in the present study we established the methods of correction for the TCI of propofol following wrong selection of emulsion concentration during the induction of anesthesia and we pharmacokinetically investigated the validity of the correction methods for each potential error situation.

\section{Materials and Methods}

In this study bench experiments were conducted, using sterile distilled water as a virtual solution for 1.0 and $2.0 \%$ propofolTCIs targeting $4.0 \mu \mathrm{g} / \mathrm{ml}$ of effect site concentration $\left(\mathrm{C}_{\text {eff }}\right)$. Three TCI workstations (Orchestra ${ }^{\circledR}$, Fresenius Vial, Le Grand Che-

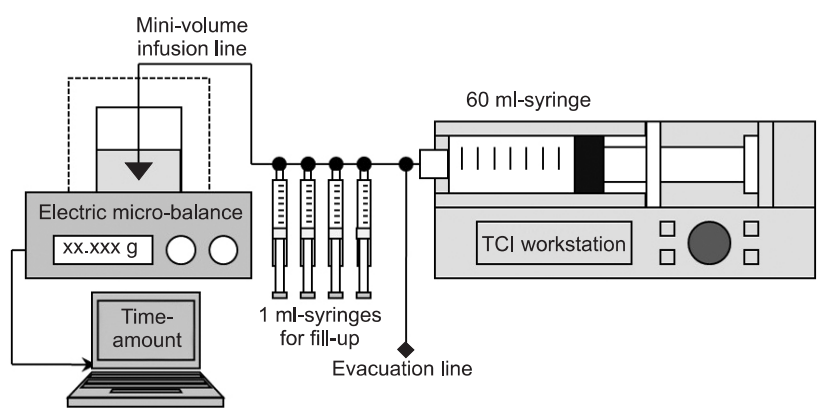

Fig. 1. Schematic diagram for the experimental corrections of the wrong target-controlled infusions (TCI) following false selections of emulsion concentration of propofol. min, Brezins, France) were randomly used. The modules were calibrated (Zero calibration: $6 \mathrm{~V} \pm 0.05 \mathrm{~V}$, Pressure calibration: 0.8 bar) before this experiment. The incorporated PK/PD model of Gepts et al. [5] and Struys et al. [6] was selected and covariates (age, gender, height) were randomly entered. The body weight was used at $5.0 \mathrm{~kg}$ intervals between 40 to $95 \mathrm{~kg}$ as the only covariate influencing the $\mathrm{PK}$ parameters in this $\mathrm{PK} / \mathrm{PD}$ model.

A diagram for this experiment is schematized in Fig. 1. A BD Plastipak compatible $60 \mathrm{ml}$ syringe (BD $60 \mathrm{ml}$ Syringe, Luer-Lok ${ }^{\mathrm{TM}}$ Tip, BD, USA) was inserted into the TCI workstation and the syringe tip was connected to a three-way stopcock. One maleside was used to evacuate fluid and the other male-side was connected to 4 three-way stopcocks serially. Four $1 \mathrm{ml}$ syringes were connected for fill up to the each stopcock and a low-compliant infusion line (M-V Extension Tubing, Ace-Medical Inc., Seoul, Korea) was connected to the last stopcock. The distal tip of this infusion line was connected to a spinal needle (Spinal Needle, 22 G $\times 89$ mm, Hakko Co., Ltd., Nagano-ken, Japan) and the needle-tip was submerged $1.0 \mathrm{~cm}$ into distilled water. A thin layer of oil was spread on the water-surface to prevent natural evaporation. The level of tip syringe was maintained at the same height as the surface of water in a sampling glass before the initiation of TCI. All infusion assemblies were carefully prepared to be filled with distilled water without air.

The TCI was started using 1.0\% virtual emulsion with wrong setting to $2.0 \%$ (FALSE $_{1-2}$ ) or using $2.0 \%$ virtual emulsion with false setting to $1.0 \%\left(\mathrm{FALSE}_{2-1}\right)$. These wrong TCI were corrected at $3 \mathrm{~min}$ after the start of infusion. Twenty-four TCIs of FALSE $_{1-2}$ were randomly assigned to 2 different fill-up corrections a manual fill-up bolus was injected after achieving a pseudo-steady state of equilibrium following a test-increase FILL $_{\text {equi, }}$ $\mathrm{n}=12$ ) or if the test-increase was overridden to the manual fillup bolus without waiting for the equilibrium $\left(\mathrm{FILL}_{\text {over }}, \mathrm{n}=12\right)$. The equilibrium state of this study was considered as a situation when $\mathrm{C}_{\text {eff }}$ became to be equal to the plasma concentration $\left(\mathrm{C}_{\mathrm{p}}\right)$. Another 24 TCIs of FALSE $_{2-1}$ were randomly assigned into two different evacuation corrections and were performed during targeting $\mathrm{C}_{\text {eff }}\left(\mathrm{EVAC}_{\mathrm{eff}}, \mathrm{n}=12\right)$ or after switching to targeting $\mathrm{C}_{\mathrm{p}}$ $\left(\mathrm{EVAC}_{\mathrm{p}}, \mathrm{n}=12\right)$. During the evacuations, the TCI continued but the infusate was directed to atmosphere and not delivered to the sampling glass. The durations of evacuation which was the context sensitive decrement time (Csdt) of $50 \%$ of $\mathrm{C}_{\text {eff }}$ and $\mathrm{C}_{\mathrm{p}}$ at 3 min, were calculated using 'Csdt' library of 'PKPD Tools for Excel' (Add-In program was available at http://pkpdtools.com/ doku.php/downloads:start, April, 2013). The sequences of each correction procedure are summarized in Table 1 and 2. The duration of the emulsion replacement was limited to $1 \mathrm{~min}$. Thereafter, TCI was maintained until the end of infusion alarm was triggered after the fill-up correction or until the end of infusion alarm for second syringe was triggered after the evacuation cor- 
Table 1. Time Courses of the Procedures of Fill-up Corrections at the Time (Time) from the Start of Correction during Wrong Targetcontrolled Infusion of 1.0\% Propofol Following False-setting to 2.0\% Propofol

\begin{tabular}{|c|c|c|}
\hline \multicolumn{2}{|c|}{ Time (min) } & \multirow{2}{*}{ Procedures } \\
\hline After equilibrium & Over-riding & \\
\hline 0.0 & 0.0 & $\begin{array}{l}\text { Test-increase of target to } 6.0 \mu \mathrm{g} / \mathrm{ml} \text {. } \\
\text { Calculate a fill-up amount. } \\
\text { Decrease target to } 4.0 \mu \mathrm{g} / \mathrm{ml} \text {. }\end{array}$ \\
\hline 6.0 & 0.33 & $\begin{array}{l}\text { Turn stopcock and Evacuation. } \\
\text { Inject fill-up bolus manually. }\end{array}$ \\
\hline 7.5 & 0.66 & $\begin{array}{l}\text { Replace } 1 \% \text { with } 2 \% \text { propofol. } \\
\text { Purge the syringe. } \\
\text { Turn stopcock to main stream. }\end{array}$ \\
\hline 8.5 & 1.66 & Start infusion. \\
\hline
\end{tabular}

Table 2. Time Course of the Procedures of Evacuation Corrections at the Time (Time) from the Start of Correction during Wrong Targetcontrolled Infusion of 2.0\% Propofol Following False-setting to $1.0 \%$ Propofol

\begin{tabular}{|c|c|c|}
\hline \multicolumn{2}{|c|}{ Time (min) } & \multirow[b]{2}{*}{ Procedures } \\
\hline $\begin{array}{l}\text { Targeting } \\
\text { effect-site }\end{array}$ & $\begin{array}{c}\text { Targeting } \\
\text { plasma }\end{array}$ & \\
\hline 0.0 & 0.0 & $\begin{array}{l}\text { Turn stopcock to evacuation line. } \\
\text { Evacuation of infusion. }\end{array}$ \\
\hline 3.85 & 2.88 & $\begin{array}{l}\text { Replace } 2 \% \text { with } 1 \% \text { propofol. } \\
\text { Purge the syringe. } \\
\text { Turn stopcock to main stream. }\end{array}$ \\
\hline 4.85 & 3.88 & Start infusion. \\
\hline
\end{tabular}

The corrections were performed during targeting effect-site or after switching to targeting plasma concentration of propofol.

Table 3. The Fill-up Corrections for the False-setting of $1.0 \%$ to $2.0 \%$ Propofol were Performed after the Equilibrium (FILL equi $_{1}$ ), or While Overriding $\left(\mathrm{FILL}_{\text {over }}\right)$. The Evacuation Corrections for False-setting of 2.0\% to 1.0\% Propofol were Performed during Targeting Effect-site Concentration $\left(\mathrm{EVAC}_{\mathrm{eff}}\right)$, or after Switching to Targeting Plasma Concentration $\left(\mathrm{EVAC}_{\mathrm{pl}}\right)$. All Corrections were Made at 3 min after the Start of Infusions

\begin{tabular}{|c|c|c|c|c|c|c|}
\hline & \multicolumn{2}{|c|}{ Fill-up correction } & \multirow[b]{2}{*}{$P$ value } & \multicolumn{2}{|c|}{ Evacuation correction } & \multirow[b]{2}{*}{$P$ value } \\
\hline & $\begin{array}{l}\text { FILL }_{\text {equi }} \\
(\mathrm{n}=12)\end{array}$ & $\begin{array}{l}\text { FILL }_{\text {over }} \\
(\mathrm{n}=12)\end{array}$ & & $\begin{array}{l}\text { EVAC }_{\text {eff }} \\
(\mathrm{n}=12)\end{array}$ & $\begin{array}{l}\mathrm{EVAC}_{\mathrm{pl}} \\
(\mathrm{n}=12)\end{array}$ & \\
\hline $\mathrm{C}_{\text {eff-3min }}(\mu \mathrm{g} / \mathrm{ml})$ & $1.98 \pm 0.016$ & $1.99 \pm 0.007$ & 1.000 & $7.99 \pm 0.036$ & $7.98 \pm 0.070$ & 1.000 \\
\hline $\mathrm{T}_{ \pm 5 \%}(\min )$ & $6.9 \pm 0.05$ & $3.9 \pm 0.25$ & $<0.001$ & $6.7 \pm 0.15$ & $3.6 \pm 0.04$ & $<0.001$ \\
\hline Fill-up bolus (mg) & $62.4 \pm 14.0$ & $62.5 \pm 13.8$ & 1.000 & - & - & - \\
\hline
\end{tabular}

Values indicate mean $\pm \mathrm{SD} . \mathrm{C}_{\text {eff-3min }}$ indicates the effect-site concentration of propofol at 3 min after the start of infusion, and $\mathrm{T}_{ \pm 5 \%}$ indicates the time to normalize within $\pm 5 \%$ of target concentration.

rection. Randomizations of this study were performed using the Microsoft ${ }^{\circledR}$ Excel randomization function. The experiment was discarded and started again in cases of fluid leakage from the infusion assembly and air delivery into sampling glass on visual inspection.

During every TCI, the weights of delivered infusate were measured using an electric micro-balance (FX-300i, A\&D Co, Ltd, Republic of Korea) with $0.001 \mathrm{~g}$ sensitivity and $1 \mathrm{~s}$ stabilization time. Data were saved in a Microsoft Excel ${ }^{\circledR}$ spreadsheet as a hard disk using RS232 interface software (RrKey Ver. 1.34, A\&D Co, Ltd., Republic of Korea) with $1 \mathrm{~s}$ data saving interval. Zero calibrations were done before each measure and the weight was converted to volume delivery assuming a conversion of 1 $\mathrm{g}$ of distilled water equaling $1.0029 \mathrm{ml}$. Water temperature was maintained within $23-25^{\circ} \mathrm{C}$. The saved data-file was converted into a file formatted as 'time' vs. 'unit infusion rate' columns. Then, the pharmacokinetic/pharmacodynamic software (STANPUMP $^{\complement}$, written by Steven L. Shafer, Palo Alto, CA, USA) read this 'drg' file using solution-specific command line arguments and external kinetic files of 1.0 and $2.0 \%$ emulsion and reproduced the actual time courses of $\mathrm{C}_{\mathrm{p}}$ and $\mathrm{C}_{\text {eff }}$.

$\mathrm{C}_{\text {eff }}$ at $3 \mathrm{~min}\left(\mathrm{C}_{\text {eff-3min }}\right)$ after the start of TCI and the time to normalize within $\pm 5 \%$ of target concentration $\left(\mathrm{T}_{ \pm 5 \%}\right)$, as the primary end-points of this experiment, were compared to evaluate the effectiveness between the methods of correction of each wrong TCI. Data are expressed as mean \pm SD. Continuous variables between corrections were compared using an independent t-test. A value of $\mathrm{P}<0.05$ was considered significant. Statistical calculations were performed using SPSS 13.0 for windows (SPSS Inc, Chicago, IL, USA).

\section{Results}

The $\mathrm{C}_{\text {eff-3min }}$ after the start of TCI were not significantly different between the sub-groups of each wrong TCI $(\mathrm{P}=1.000)$ (Table 3). Time courses of the reproduced actual concentration of propofol are illustrated in Fig. 2 and 3. Data were expressed until $30 \mathrm{~min}$ after the start of infusion. Gray bands indicate the range of $\pm 5 \%$ of the target concentration.

In FALSE ${ }_{1-2}$, the test-increase of target to $6.0 \mu \mathrm{g} / \mathrm{ml}$ led to $\mathrm{C}_{\text {eff }}$ increase to $2.98 \pm 0.03 \mu \mathrm{g} / \mathrm{ml}$ during the fill-up corrections of FILL $_{\text {equi, }}$ and the calculated fill-up amount was $62.4 \pm 14.0 \mathrm{mg}$. Therefore, $3.1 \pm 0.7 \mathrm{ml}$ of virtual infusate was manually injected, which increased $\mathrm{C}_{\text {eff }}$ to $4.24 \pm 0.33 \mu \mathrm{g} / \mathrm{ml}$ (Fig. 2A). During the fill-up corrections of $\mathrm{FILL}_{\text {over }}$, the calculated fill-up amount was $62.5 \pm 13.8 \mathrm{mg}$ which override the test-increase and led $\mathrm{C}_{\text {eff }}$ to be 
A

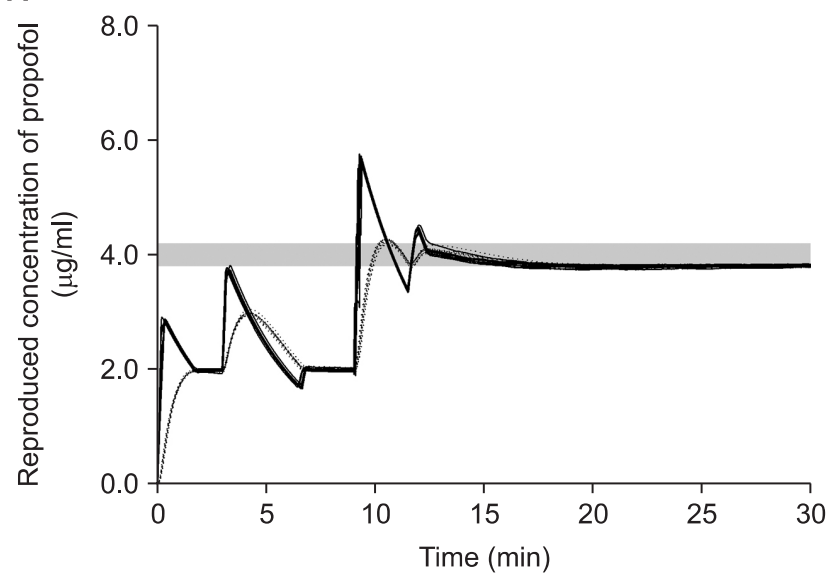

B

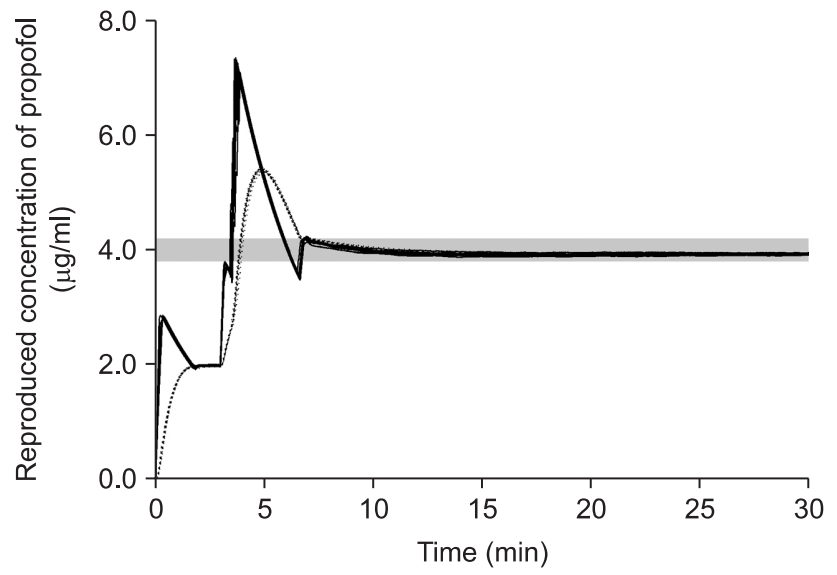

Fig. 2. The reproduced actual plasma (solid lines) and effect-site (dotted lines) concentration during targeting $4.0 \mu \mathrm{g} / \mathrm{ml}$ of effect-site concentration using $1.0 \%$ virtual emulsion with false setting to $2.0 \%$ propofol, and the fill-up corrections were performed after achieving the equilibrium (A) or overriding together (B). Gray bands indicate the range of $\pm 5 \%$ of the target concentration.

A

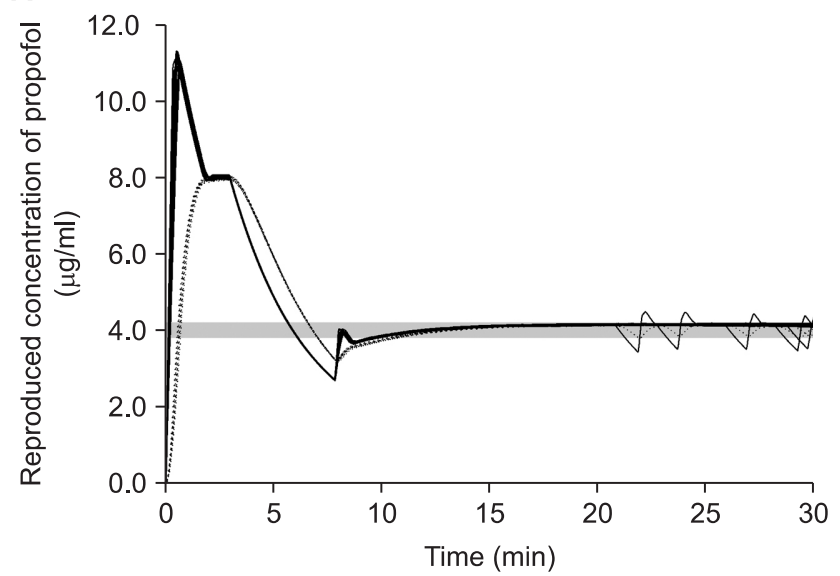

B

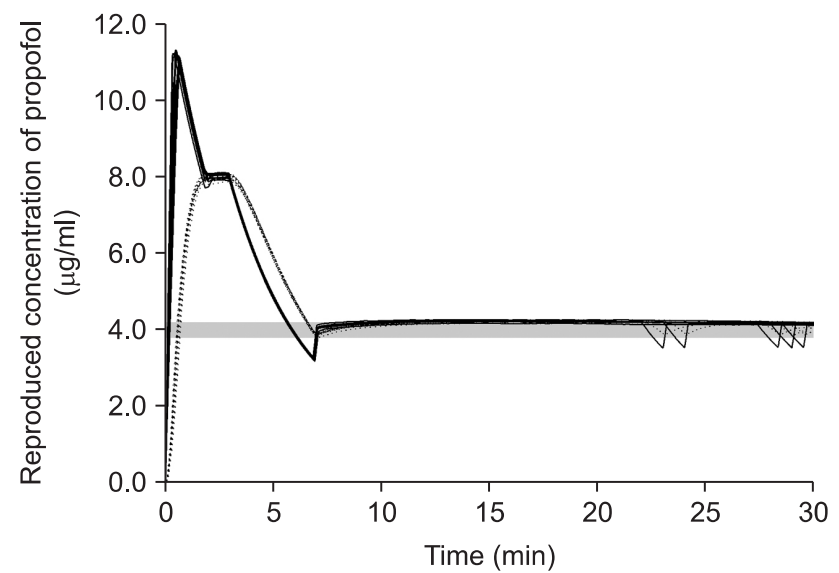

Fig. 3. The reproduced actual plasma (solid lines) and effect-site (dotted lines) concentration during targeting $4.0 \mu \mathrm{g} / \mathrm{ml}$ of effect-site concentration using $2.0 \%$ virtual emulsion with false setting to $1.0 \%$ propofol, and the evacuation corrections were performed during targeting effect-site concentration (A), or after switching to targeting plasma concentration (B). Gray bands indicate the range of $\pm 5 \%$ of the target concentration.

overshot to $5.4 \pm 0.02 \mu \mathrm{g} / \mathrm{ml}$ (Fig. $2 \mathrm{~B}$ ). $\mathrm{T}_{ \pm 5 \%}$ of FILL $\mathrm{Fver}_{\text {was }}$ significantly shorter than that of $\mathrm{FILL}_{\text {equi }}(\mathrm{P}<0.001)$ (Table 3).

During the evacuation corrections, $\mathrm{EVAC}_{\text {eff }}$ led $\mathrm{C}_{\text {eff }}$ to $4.0 \pm$ $0.02 \mu \mathrm{g} / \mathrm{ml}$ after $3.85 \mathrm{~min}$ of evacuation, then $\mathrm{C}_{\text {eff }}$ decreased to $3.2 \pm 0.02 \mu \mathrm{g} / \mathrm{ml}$ and $C_{p}$ also decreased to $2.7 \pm 0.03 \mu \mathrm{g} / \mathrm{ml}$ during the drug replacement (Fig. $3 \mathrm{~A}$ ). $\mathrm{EVAC}_{\mathrm{pl}}$ led $\mathrm{C}_{\mathrm{p}}$ to $4.0 \pm 0.03$ $\mu \mathrm{g} / \mathrm{ml}$ after $2.88 \mathrm{~min}$ of evacuation, then $\mathrm{C}_{\text {eff }}$ decreased to $3.9 \pm$ $0.04 \mu \mathrm{g} / \mathrm{ml}$ and $\mathrm{C}_{\mathrm{p}}$ decreased to $3.3 \pm 0.08 \mu \mathrm{g} / \mathrm{ml}$ during the drug replacement (Fig. $3 \mathrm{~B}$ ). $\mathrm{T}_{ \pm 5 \%}$ of $\mathrm{EVAC}_{\mathrm{pl}}$ was significantly shorter than that of $\operatorname{EVAC}_{\text {eff }}(\mathrm{P}<0.001)$ (Table 3$)$.

\section{Discussion}

The wrong TCI following false-setting to higher emulsion concentration of propofol could be effectively corrected using the fill-up method during targeting $\mathrm{C}_{\text {effi }}$ and the false setting to lower concentration could be corrected using the evacuation method after switching to targeting $\mathrm{C}_{\mathrm{p}}$ of propofol.

Propofol is known to have a linear pharmacokinetic [5]. Therefore, TCI with wrong settings between 1.0 and $2.0 \%$ emulsion concentrations have shown double or half of the target concentration like the results of this study. These wrong selections could be easily detected or possibly neglected during the early phase of anesthesia induction. When the emulsion concentration is falsely selected to higher concentration, the loss of consciousness (LOC) will be delayed or hardly induced. When a lower concentration is falsely selected, the patient will show a faster LOC or more hemodynamic depressions. Therefore, the 
simulation scenario of correction at 3 min after the start of infusion was choosen.

During preliminary experiments before this study, we tried to correct the wrong TCI due to a simple replacement to the correct emulsion concentration which was identical to a starting concentration. But, in order to normalize $\mathrm{C}_{\text {eff }}$ to be within $\pm 5 \%$ of the target, it took $19.5 \mathrm{~min}$ for the false setting of 1.0 to $2.0 \%$ propofol and $54.4 \mathrm{~min}$ for the false setting of 2.0 to $1.0 \%$ (Fig. 4). In addition, the TCI could not provide accurate information on the predicted concentrations during the period of normalization. Moreover, it might become more confused if we alter the target concentration during this normalization period. Therefore, we investigated the correction methods based on the pharmacokinetic and pharmacodynamic of propofol in order to normalize rapidly and effectively. The sequences of each correction were as followings; (1) estimation of the amount to fill-up or the duration to evacuate (2) correction (3) emulsion replacement to the correct concentration.

For the fill-up corrections, we anticipated that the amount of propofol needed to increase $2.0 \mu \mathrm{g} / \mathrm{ml}$ to $4.0 \mu \mathrm{g} / \mathrm{ml}$ might be the same as that needed to increase $4.0 \mu \mathrm{g} / \mathrm{ml}$ to $6.0 \mu \mathrm{g} / \mathrm{ml}$. After estimating the amount for fill-up using a test increase of $4.0 \mu \mathrm{g} /$ $\mathrm{ml}$ to $6.0 \mu \mathrm{g} / \mathrm{ml}$, we waited until the pseudo-steady state of equilibrium in order to validate the correction method. Then the fillup bolus led $\mathrm{C}_{\text {eff }}$ to $4.24 \mu \mathrm{g} / \mathrm{ml}$, which was about $6 \%$ higher than expected. However, in clinical settings, it is not a short period to wait until the pseudo-steady state of equilibrium. Therefore, the method of overriding correction could more rapidly normalize the wrong TCI. The overshot of $\mathrm{C}_{\text {eff }}$ might be anticipated, but the maximum $\mathrm{C}_{\text {eff }}$ after the fill-up bolus was $5.41 \mu \mathrm{g} / \mathrm{ml}$.

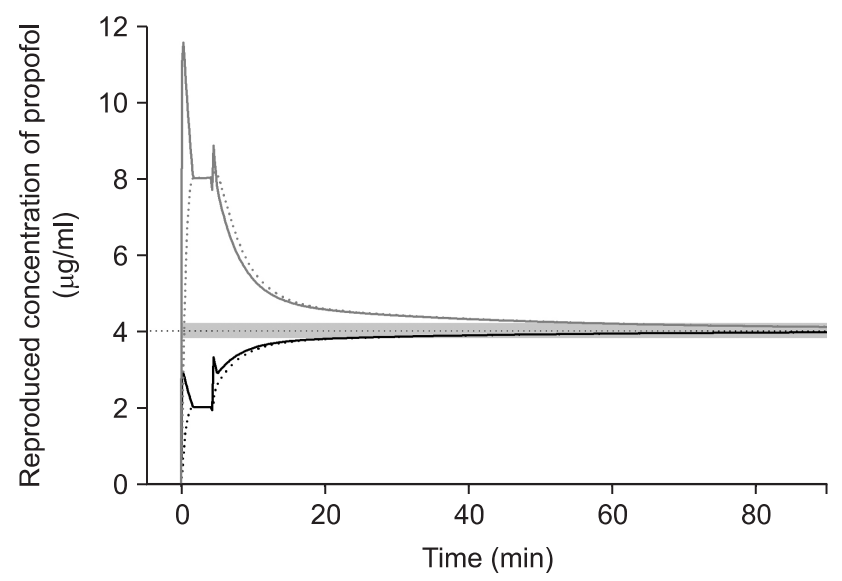

Fig. 4. The reproduced actual plasma (solid lines) and effect-site (dotted lines) concentration during targeting $4.0 \mu \mathrm{g} / \mathrm{ml}$ of effect-site concentration using $1.0 \%$ virtual emulsion with false setting to $2.0 \%$ propofol (black lines), or using $1.0 \%$ virtual emulsion with false setting to $2.0 \%$ (gray lines). The simple corrections were performed at $3 \mathrm{~min}$ after the start of infusion. Gray bands indicate the range of $\pm 5 \%$ of the target concentration.
The TCI workstation used in this study shows Csdt for $\mathrm{C}_{\text {eff }}$ rounding off below the decimal point. For example, it displays Csdt between $1.45 \mathrm{~min}$ to $2.44 \mathrm{~min}$ as $2.0 \mathrm{~min}$. Therefore, we used a simulation software (PKPD Tools for Excel) to calculate accurate durations of evacuation for $\mathrm{C}_{\mathrm{p}}$ and $\mathrm{C}_{\mathrm{eff}}$. The evacuation correction was performed based on the time point where the time required to decrease $\mathrm{C}_{\mathrm{p}}$ and $\mathrm{C}_{\text {eff }}$ to a certain degree would be identical and irrelevant to maintaining concentrations, but relevant to the duration of infusion [7]. Csdt of $8.0 \mu \mathrm{g} / \mathrm{ml}$ to $4.0 \mu \mathrm{g} / \mathrm{ml}$ at $3 \mathrm{~min}$ of TCI would be identical to that of $4.0 \mu \mathrm{g} /$ $\mathrm{ml}$ to $2.0 \mu \mathrm{g} / \mathrm{ml}$. Eventually, $\mathrm{C}_{\mathrm{p}}$ and $\mathrm{C}_{\text {eff }}$ decreased to $4.0 \mu \mathrm{g} / \mathrm{ml}$ after Csdt- $\mathrm{C}_{\mathrm{p}}$ and Csdt- $\mathrm{C}_{\text {eff. }}$ But the $\mathrm{C}_{\mathrm{p}}$ decreases faster than the $\mathrm{C}_{\text {eff }}$ after cessation of infusion $[8,9]$. Therefore, during $\mathrm{EVAC}_{\text {eff }}$, $\mathrm{C}_{\mathrm{p}}$ would be lower than $\mathrm{C}_{\text {eff }}$ after Csdt- $\mathrm{C}_{\text {eff }}$, but the wrong TCI would regard this status as a pseudo-equilibrium state. Accordingly, the $\mathrm{C}_{\mathrm{p}}$ could be over-predicted around the emulsion replacement. However during $\mathrm{EVAC}_{\mathrm{p}}$, the TCI system would not miss the time course of $\mathrm{C}_{\mathrm{p}}$ and more accurately infuse the deficit during the drug replacement.

However, there were some limitations in our experiment. First, as discussed earlier in our previous report [3], the corrections were performed on the basis of the concentration of central compartment $\left(\mathrm{C}_{\mathrm{p}}\right)$ and $\mathrm{C}_{\text {eff. }}$ But the pharmacokinetic model of this study was not a one compartment model but a three compartment model. Therefore, the correction methods were not perfect, even though they were rapid. Simulations of the concentration of three compartments using PK/PD software showed that the TCI following falsely selected to higher concentration setting and predicted the concentrations of the peripheral compartments to be higher as well as $C_{p}$ (Fig. 5).

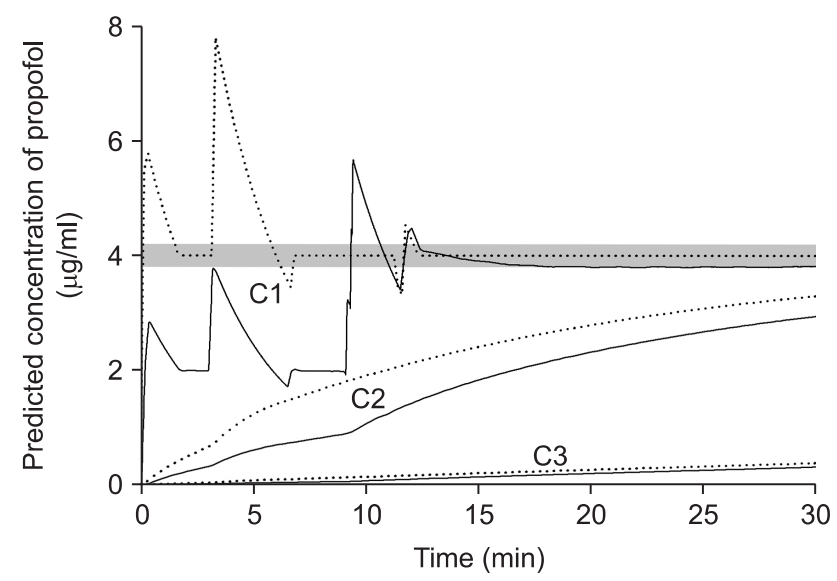

Fig. 5. The nominal (dotted lines) and reproduced actual (solid lines) predicted plasma concentrations at the central compartment, $\mathrm{C} 1$ (upper), and at two peripheral compartments, C2 (middle), and C3 (lower) targeting $4.0 \mu \mathrm{g} / \mathrm{ml}$ of effect-site concentration, and the false setting of $1.0 \%$ virtual emulsion to $2.0 \%$ was corrected after achieving the equilibrium state. Gray bands indicate the range of $\pm 5 \%$ of the target concentration. 
These differences at the peripheral compartments are considered to be the cause of the small amount of over-correction after the manual bolus during the fill-up correction and led to a slight decrease of $\mathrm{C}_{\text {eff-rep }}$ after the drug replacement. On the contrary, TCI following falsely selected to lower concentration predicted the concentration of the peripheral compartments to be lower as well as $\mathrm{C}_{\mathrm{p}}$. Therefore, the $\mathrm{C}_{\text {eff-rep }}$ after the drug replacement slightly increased, then approached to the target. However, the mean deviations from the target were within the range of $\pm 5.0 \%$. Second, some clinicians might consider the correction methods of this study to be more complicated than just imaging the predicted concentrations to be double or half of the concentrations displayed on the TCI workstation. And this method could be useful for a short duration of infusion but might be not suitable for a long duration of anesthesia. Third, in this study, we used distilled water as virtual emulsion. Therefore, we did not replace the emulsion to correct concentrations, and waited just $1 \mathrm{~min}$ to simulate the syringe replacement time in clinical circumstances. Also, the gravimetrically measured amount was converted into the correct concentration of propofol during the simulation.

The purpose of this study was to investigate the risk management for an erroneous situation during TCI. There is no doubt that it is essential to pay attention to the preparation of TCI. Also the wrong selection of the drug emulsion concentration may not be frequent in clinical settings. However, if we know how to handle possible error situations in advance we will be able to effectively deal with those issues.

\section{References}

1. Neff T, Fischer J, Fehr S, Baenziger O, Weiss M. Start-up delays of infusion syringe pumps. Paediatr Anaesth 2001; 11: 561-5.

2. Kim JY, Moon BK, Lee JH, Jo YY, Min SK. Impact of priming the infusion system on the performance of target-controlled infusion of remifentanil. Korean J Anesthesiol 2013; 64: 407-13.

3. Chae YJ, Kim JY, Kim DW, Moon BK, Min SK. False selection of syringe-brand compatibility and the method of correction during targetcontrolled infusion of propofol. Korean J Anesthesiol 2013; 64: 251-6.

4. Glen JB. The development of 'Diprifusor': a TCI system for propofol. Anaesthesia 1998; 53 Suppl 1: 13-21.

5. Gepts E, Camu F, Cockshott ID, Douglas EJ. Disposition of propofol administered as constant rate intravenous infusions in humans. Anesth Analg 1987; 66: 1256-63.

6. Struys MM, De Smet T, Depoorter B, Versichelen LF, Mortier EP, Dumortier FJ, et al. Comparison of plasma compartment versus two methods for effect compartment--controlled target-controlled infusion for propofol. Anesthesiology 2000; 92: 399-406.

7. Hughes MA, Glass PS, Jacobs JR. Context-sensitive half-time in multicompartment pharmacokinetic models for intravenous anesthetic drugs. Anesthesiology 1992; 76: 334-41.

8. Shafer SL, Varvel JR. Pharmacokinetics, pharmacodynamics, and rational opioid selection. Anesthesiology 1991; 74: 53-63.

9. Bailey JM. Technique for quantifying the duration of intravenous anesthetic effect. Anesthesiology 1995; 83: 1095-103. 